\title{
Soil moisture variability and its influence on convective precipitation over complex terrain
}

\author{
Christian Hauck ${ }^{\mathrm{a}, \mathrm{b} *}$, Christian Barthlott ${ }^{\mathrm{a}}$, Liane Krauss ${ }^{\mathrm{a}}$, and Norbert Kalthoff ${ }^{\mathrm{a}}$ \\ ${ }^{a}$ Institute for Meteorology and Climate Research, Karlsruhe Institute of Technology (KIT), Germany \\ ${ }^{\mathrm{b}}$ Department of Geosciences, University of Fribourg, Switzerland \\ ${ }^{*}$ Correspondence to: C. Hauck, Department of Geosciences, University of Fribourg, Chemin du Musée 4, CH-1700 \\ Fribourg, Switzerland. E-mail: christian.hauck@unifr.ch
}

\begin{abstract}
Soil moisture monitoring data from the Convective and Orographically-induced Precipitation Study (COPS) 2007 are combined with operational and high-resolution simulations with the weather forecast system GME/COSMO-DE to analyse the discrepancies between observed and modelled soil moisture fields and their potential impacts on convective precipitation forecasts. We use data from the newly installed soil moisture monitoring network comprising 47 stations with soil moisture sensors installed at three different depths within the COPS area in southwest Germany. The obtained soil moisture fields are compared to their related representation within the global model GME interpolated with high-resolution soil and surface data to a $2.8 \mathrm{~km}$ resolution yielding soil moisture values on the same grid as the high-resolution model COSMO-DE. Systematic differences between modelled and measured soil moisture values are found and used to determine the potential impact of large soil moisture biases for the modelling of convective processes. This is achieved by conducting sensitivity tests using COSMO-DE, in which the initialisation fields of soil moisture are varied. Results show a general mean bias towards too dry soil conditions, both in GME during the whole COPS period, as well as in the high-resolution modelling of specific COPS IOPs with COSMO-DE. The influence of this bias on simulated precipitation is significant and non-trivial and depends on the specifics of the analysed case study. The results presented in this study demonstrate that soil moisture has a considerable impact on convectionrelated parameters over complex and heterogeneous terrain, but that no simple relationship regarding the sign of the soil moisture-precipitation feedback could be identified due to a complex interplay between various factors that favour or inhibit convection initiation.
\end{abstract}

Key Words: COPS; soil moisture monitoring network; COSMO model; Black Forest; convection initiation

Citation: Hauck C, Barthlott C, Krauss L, Kalthoff N. 2011. Soil moisture variability and its influence on convective precipitation over complex terrain. Q. J. R. Meteorol. Soc. 137: 42-56. DOI:10.1002/qj.766

1. Introduction

Quantitative precipitation forecasting (QPF) is a challenge for state-of-the-art numerical weather prediction (NWP) models. In particular, the prediction of convective precipitation over complex terrain under weak synoptic controls is still inadequate, one of the potential uncertainties being the influence of soil conditions, such as soil moisture and/or soil texture, and their relative importance in different regions. Under weak synoptic controls, low-level 
and boundary-layer moisture inhomogeneities (Weckwerth, 2000) as well as convergence zones of different origin (e.g. Ulanski and Garstang, 1978; Wilson and Schreiber, 1986) can be important factors, but also spatial inhomogeneities of land use and/or soil moisture have been identified as important processes in recent years (Taylor and Ellis, 2006; Baldi et al., 2008; Gantner and Kalthoff, 2010).

Soil moisture influences a number of processes concerning land-atmosphere interaction on different spatial and temporal scales (Seneviratne et al., 2006; Fischer et al., 2007). Observational and modelling studies have also shown how soil moisture can affect daily (Taylor and Lebel, 1998; Clark et al., 2004) and weekly (Koster et al., 2004) rainfall. Some of these processes concern the initiation of convection and the subsequent possibility of convective precipitation, such as the influence on the surface temperature and the availability of moisture in the planetary boundary layer (PBL) (e.g. Koster et al., 2000; Hohenegger et al., 2009). The PBL characteristics and their impacts on the triggering and/or dynamics of convective storms are strongly influenced by the partitioning of available radiation energy into sensible and latent heat, which itself is determined by soil moisture. Whereas for homogenoeus areas with scarce vegetation the impact of soil moisture on convection-related parameters and convective precipitation is well documentated (e.g. Taylor and Lebel, 1998; Taylor et al., 2007; Kohler et al., 2010), it is generally not clear how large the influence of soil moisture for different geographic regions and seasons is, especially in complex (concerning e.g. surface characteristics and/or orography) terrain.

Concerning convective precipitation, the theory of the soil moisture-precipitation feedback (Pal and Eltahir, 2001) predicts an increase of the total energy of the PBL for wet soil conditions. This increase is expected to result in an increase of the convective available potential energy (CAPE). Similarly, regional climate simulations on the continental scale revealed that higher values of soil moisture lead to an enhanced amount of evapotranspiration, which is supposed to be responsible for more intense convective rainfall (Schär et al., 1999; Koster et al., 2004; Seneviratne et al., 2006). It is assumed that a positive feedback mechanism between initial soil moisture and future rainfall exists: wet soils favour the build-up of shallow boundary layers with high values of lowlevel entropy by concentrating the surface fluxes of heat and moisture into a comparatively small volume of air (Schär et al., 1999; Pal and Eltahir, 2001; Alonge et al., 2007). This mechanism provides a source of convective instability.

In contrast to this, enhanced soil moisture may decrease the daily temperature range by increasing daytime surface evaporative cooling. By this, the probability for convective precipitation is decreased due to a lack of sufficient thermal forcing to initiate convection, especially for an already humid atmosphere (Pan et al., 1996; Dai et al., 1999). On larger spatial scales, mesoscale circulations generated from discontinuities in land-surface wetness can have a stronger impact than turbulent fluxes on the formation of clouds and subsequent precipitation (e.g. Schädler, 1990; Chen and Avissar, 1994; Taylor et al., 2007).

Whereas the above statements are true for flat and comparatively homogeneous terrain, there are only few studies analysing the influence of soil moisture on convective precipitation over complex terrain. Hohenegger et al. (2009) presented a comparison of simulated soil moisture-precipitation feedback between a cloud-resolving model with explicit convection and a model with $25 \mathrm{~km}$ grid spacing and parametrized convection. Significant differences between the two models were found, with a negative feedback for the former and a strong positive feedback for the latter system. It was shown that the sensitivity of convection to the presence of a stable layer on top of the PBL is much stronger for the cloud-resolving model, leading to a strong dependence of convection initiation (CI) on the presence of sufficient thermal forcing.

The uncertainty regarding the influence of soil moisture variability on atmospheric parameters on smaller scales concerns (a) operational forecast models, where soil moisture is often treated as a numerical parameter to constrain modelled $2 \mathrm{~m}$ temperature and humidity fields to observations, and (b) field observations, where the uncertainty of temporal and spatial soil moisture variability and its influence on atmospheric variables is high, as soil moisture is not directly operationally measured on a larger grid. However, with the increasing availability of soil moisture measurements, the use of realistic soil moisture initialisation is more often applied in long-range forecasting (e.g. Vitart et al., 2008; Koster et al., 2009), following from the assumption that such better initialisation will improve forecasts. Not surprisingly, it was found that larger initial soil moisture anomalies are more likely to contribute to a more accurate precipitation and air temperature forecast (Koster et al., 2010). In this context, remote-sensing-based approaches such as the scatterometer (e.g. Naeimi et al., 2009; Wagner et al., 2009) or the newly launched Soil Moisture and Ocean Salinity mission (SMOS; Kerr et al., 2001; Kerr, 2007) may improve the availability of initial soil moisture fields, as they can deliver global soil moisture with a regional-scale support. However, these approaches have usually a sensing depth of only a few $\mathrm{cm}$ whereas the soil moisture data of greatest relevance to many applications span a much larger depth. In addition, remotely sensed soil moisture products exhibit varying accuracy depending on the respective retrieval algorithms, the resulting soil moisture product, the calibration/validation procedure, and the region where the retrieval algorithm was validated. The scaling properties of soil moisture are usually highly variable in time, which implies that remotely sensed soil moisture fields obtained on specific spatio-temporal scales cannot be easily compared to surface measurements on other scales (Brunsell and Gillies, 2003; Jones and Brunsell, 2009).

As stated above, in most operational atmospheric models the simulated prognostic variable 'soil moisture' does not have an unambiguous meaning (Koster et al., 2009). It is a strongly model-specific quantity with a dynamic range defined by the specific model formulation and the soil parameters such as porosity, hydraulic conductivity, wilting point, and layer depth, which are not known on the model scale. Whereas the absolute value of the quantity (soil moisture, saturation, wetness, water content of the root zone, etc.) has usually no direct observational analogue, its temporal variability at least tends to be similarly simulated by different models (Koster et al., 2009). However, for regional to local scales, validation data from observations are usually lacking, leaving the assessment of the importance of correct initialisation fields of soil moisture for temperature and precipitation forecasts to be highly speculative.

To overcome this deficiency in systematic model and field studies over complex terrain, a soil moisture monitoring network was installed in southwest Germany during 


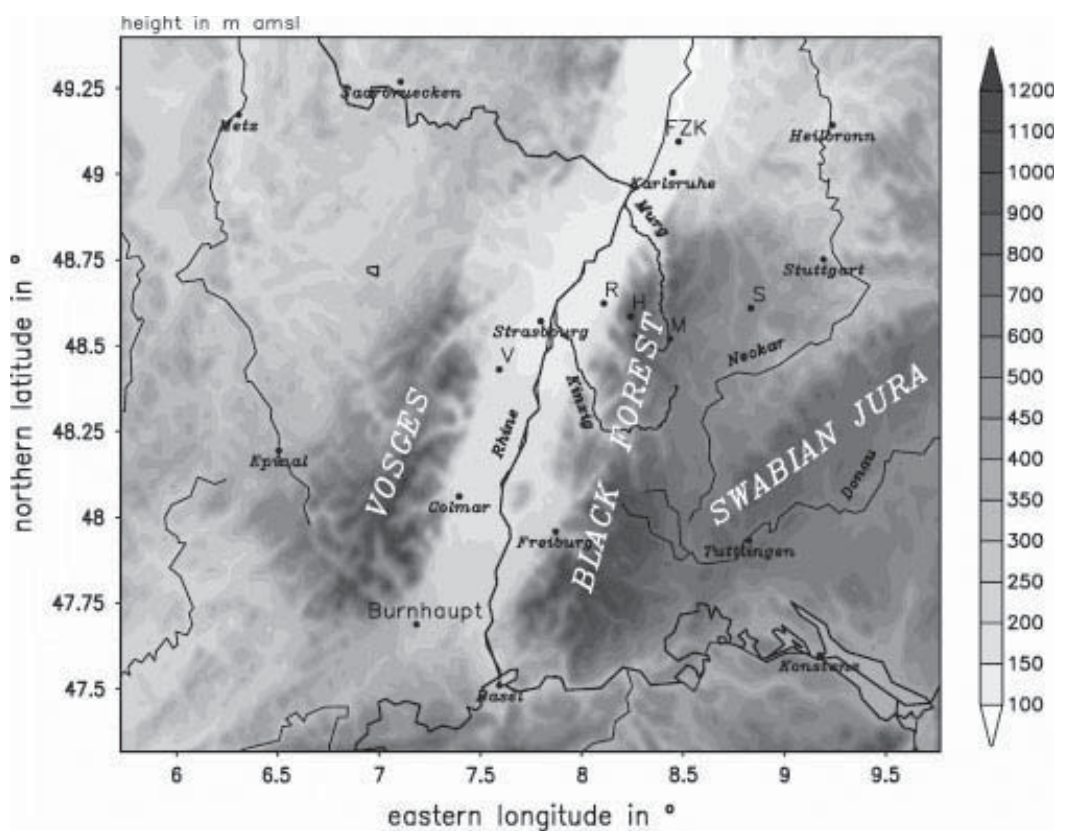

Figure 1. The COPS domain in southwest Germany and eastern France with supersites V, R, H, M, S (see text for explanation) and additional radiosonde stations at Burnhaupt le Bas and Forschungszentrum Karlsruhe (FZK). The northern and southern Black Forest are separated by the Kinzig valley.

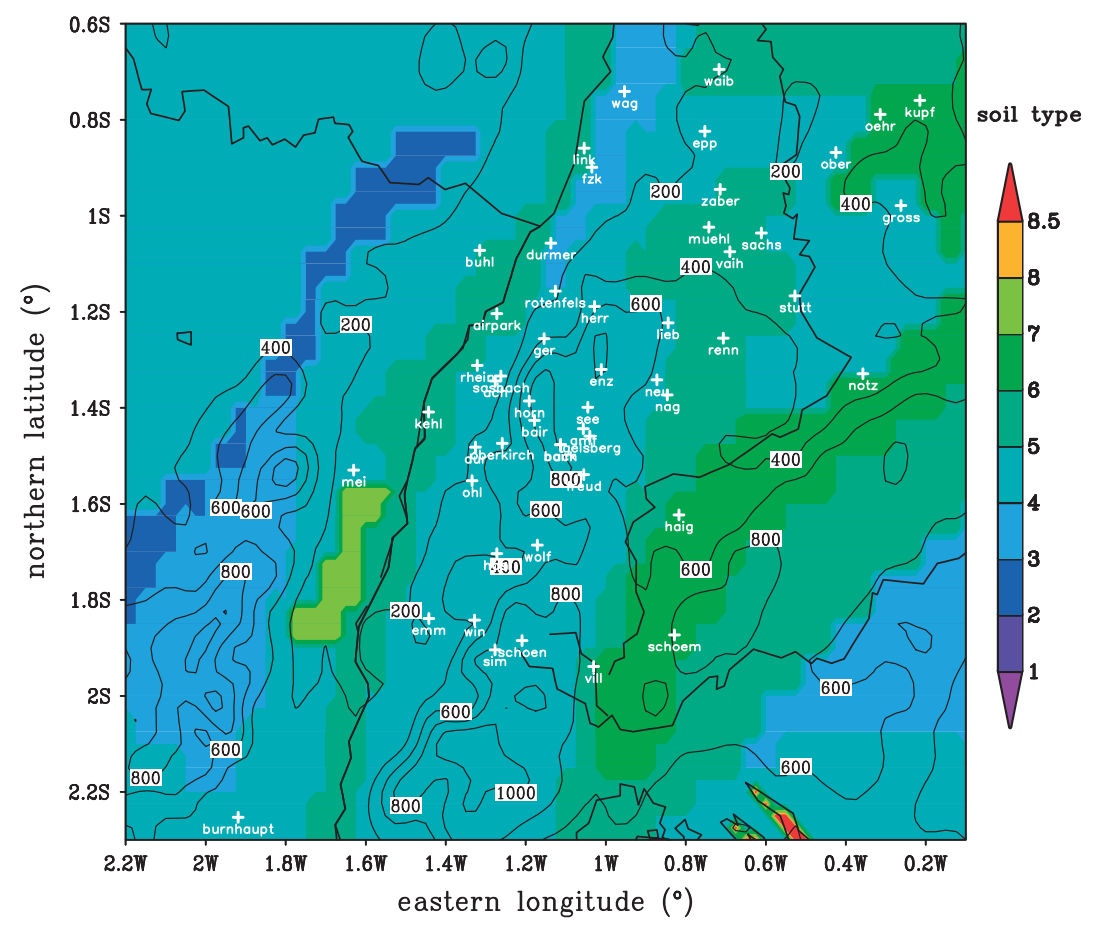

Figure 2. Soil moisture network during COPS and distribution according to soil texture (colour shading) in the COSMO model (3: sand, 4: sandy loam, 5: loam, 6: loamy clay, 7: clay, 8: peat). The black contours show terrain altitude (m). This figure is available in colour online at wileyonlinelibrary.com/journal/qj

the international Convective and Orographically-induced Precipitation Study (COPS) in summer 2007, where availability of additional atmospheric data was exceptionally high. In contrast to most atmospheric monitoring networks within COPS, the soil moisture network was installed for several years to allow also longer-term analyses of soil moisture-precipitation processes (Krauss et al., 2010). In this study, we will focus on the three-month COPS period (1 June 2007-31 August 2007) to analyse systematic differences between modelled and measured soil moisture values and to analyse the potential impact of large soil moisture biases for the modelling of convective processes. To investigate the impacts of soil moisture on the characteristics of convective storms, sensitivity tests are conducted using the Consortium for Small-scale Modeling (COSMO) model, in which the initialisation fields of soil moisture are varied.

\section{Soil moisture monitoring network during COPS}

The COPS study (Wulfmeyer et al., 2008) was performed from 1 June to 31 August 2007 in southwestern Germany and eastern France (Figure 1). In summertime, this region 
is often characterised by severe thunderstorm activity with low QPF skill. The overall goal of COPS was to advance the quality of forecasts of orographically induced convective precipitation by four-dimensional observations and modelling of its life cycle. Five supersites with a large number of different observation systems were deployed along a transect through the COPS region, named V (Vosges), R (Rhine valley), $\mathrm{H}$ (Hornisgrinde), $\mathrm{M}$ (Murg valley), and $\mathrm{S}$ (Dornstetten close to Stuttgart) (Figure 1). Two additional radiosonde stations at Forschungszentrum Karlsruhe (FZK) and Burnhaupt le Bas provided information about the vertical structure of the atmosphere at the northern and southern borders of the COPS region. An overview of the complete set-up of instruments operated is given by Kottmeier et al. (2008) and Wulfmeyer et al. $(2008,2011)$.

As part of COPS, an operational soil moisture monitoring network consisting of permanent and COPS-specific soil moisture stations was installed (Figure 2). The soil moisture network operated by the Institute for Meteorology and Climate Research (IMK) of the Karlsruhe Institute of Technology (KIT) included 47 soil moisture monitoring stations with more than 150 single soil moisture sensors deployed at three different depths $(5,20$ and $50 \mathrm{~cm})$ along a vertical profile at each station. (At some stations an additional near-surface sensor was installed.) For this, an innovative and cost-effective soil moisture sensor, the socalled Simplified Soil Moisture Probe (SISOMOP), was developed in co-operation with the Soil Moisture Group (SMG) of KIT. Measurement frequency is $10 \mathrm{~min}$. The relative accuracy of the sensor has been estimated to lie within $\pm 4 \%$. As for all soil moisture sensors, the determination of absolute soil moisture values requires a soil-specific calibration, which is described in detail in a companion paper by Krauss et al. (2010), where also further details on the performance of the network are given.

\section{Models and simulations}

In order to perform both long-term comparison of the soil moisture measurements with model results over the whole COPS period, and process analyses using high-resolution simulations of individual case-studies, the complete model chain of the German Weather Service (Deutscher Wetterdienst, DWD) including the hydrostatic global model GME, and the two non-hydrostatic limitedarea atmospheric prediction models COSMO-EU and COSMO-DE was used. Whereas both the GME and the COSMO-EU use a parametrization scheme for convective processes, convection is resolved in COSMO-DE.

The global model GME is a hydrostatic NWP model operating on a triangular grid with a mesh size of $40 \mathrm{~km}$. The model has 40 layers as well as a 7-layer soil model including freezing/melting of soil water and a sea ice model. Majewski et al. (2002) provide a more detailed description of GME. GME model data were used to compare measured and modelled soil moisture values because, in contrast to the operational non-hydrostatic COSMO-EU, in GME no assimilation scheme is used which adjusts soil moisture such that errors in near-surface temperature are minimised. To compensate for the coarse spatial scale of the GME, GME data were interpolated on a grid with $2.8 \mathrm{~km}$ horizontal resolution using the interpolation routine int $2 \mathrm{~lm}$ of DWD. (Details of the interpolation scheme can be found in Schättler, 2009). Applying this procedure, a number of important parameters, e.g. fraction of land, soil texture, surface height and roughness, plant cover and root depth were considered with $2.8 \mathrm{~km}$ resolution yielding soil moisture values on the same grid as the high-resolution model COSMO-DE. For the soil moisture comparison of this study, the operational analysis data of the GME runs during the COPS period were used.

The high-resolution simulations were performed with the non-hydrostatic limited-area atmospheric prediction model COSMO-DE (version 4.0) of the DWD (Schättler et al., 2008), also in a version without artificial soil moisture adjustment. The model employs an Arakawa C-grid for horizontal differencing on a rotated latitude/longitude grid with a horizontal resolution of $2.8 \mathrm{~km}$ which allows for turning off the parametrization of deep convection. Shallow convection is parametrized using a modified Tiedtke scheme. The number of vertical layers in a generalised terrainfollowing coordinate is 50. A six-class graupel scheme is used for microphysics, a turbulent kinetic energy (TKE) scheme for turbulence, and a two-time-level Runge-Kutta method for the dynamics. The connection between soil and atmosphere is established through the energy balance equation, whereas the required soil parameters are calculated with the multi-layer soil model TERRA-M (Heise et al., 2003; Doms et al., 2007; Warrachi-Sagi et al., 2008). Initial and hourly boundary data come from the COSMO-EU forecast with $7 \mathrm{~km}$ grid resolution, the initial time was 0000 UTC for all model runs and the simulation period was $24 \mathrm{~h}$. Apart from Germany, Switzerland, and Austria, the simulation domain contains smaller parts of bordering countries covering an area of $\sim 1200 \times 1300 \mathrm{~km}^{2}(421 \times 461$ grid points).

Simulations were conducted for various Intensive Observation Periods (IOPs) of COPS. Here, we focus on three well-documented case-studies, IOP $4 \mathrm{~b}$ on 20 June 2007, IOP 8b on 15 July 2007 and IOP 9c on 20 July 2007, which are described in detail in Kottmeier et al. (2008) and which correspond to three different trigger mechanisms for CI: large-scale lifting of potentially unstable air masses (4b), locally initiated convection (8b) and convection near convergence lines (9c). After comparing the modelled and measured soil moisture values, additional sensitivity simulations with increased and decreased initial soil moisture values were conducted to analyse the impact of erroneous initial soil moisture values on the energy balance, convective indices and precipitation. Apart from a reference run with unchanged initial soil moisture fields, sensitivity experiments with dry $(-25 \%)$ and wet $(+25 \%)$ initial soil moisture were performed for the respective COPS IOP days. The value of $25 \%$ was selected because the mean (percental) bias between observed and modelled soil moisture lies in the range of $20-30 \%$ (see below). It has to be pointed out that this modification was not done by subtracting or adding $25 \%$ volumetric water content (VWC in \%), but by multiplying the initial soil moisture values of the reference run with 0.75 and 1.25 , respectively. In this focus on observed misfits between observed and modelled soil moisture values, our study differs from other model sensitivity approaches, where soil moisture is often varied between the possible minimum and maximal values, i.e. wilting point and field capacity, respectively (Jones and Brunsell, 2009). 


\section{Results}

\subsection{Comparison of soil moisture measurements with GME} and COSMO-DE simulation results

\subsubsection{Long-term temporal and spatial variability of soil} moisture

3-hourly GME analysis data after interpolation on the COSMO-DE grid were compared to coincident soil moisture measurements at all stations of the network. Hereby, only measurement data passing a quality control protocol were chosen for comparison. From Figure 3(a), it can be seen that this is usually the case for 25-35 stations during most of the COPS period.

Figure 3 shows the temporal evolution of the mean bias (MB) and root mean square error (RMSE) over the whole COPS domain, where

$$
M B=\frac{1}{N} \sum_{i=1}^{N}\left(\theta_{\text {sim }, i}-\theta_{\text {meas }, i}\right)
$$

and

$$
R M S E=\sqrt{\frac{1}{N} \sum_{i=1}^{N}\left(\theta_{\text {sim }, i}-\theta_{\text {meas }, i}\right)^{2}},
$$

where $\theta_{\text {sim }}$ and $\theta_{\text {meas }}$ are modelled and observed soil moisture (in \% by volume) for each time instance and each soil moisture station $i$, and $N$ is the number of available stations for each time step.

With a mean bias of minus $5-10 \%$ for the uppermost sensor, the differences are quite large, but are not surprising regarding the order of magnitude as the low-resolution forcing of GME cannot simulate the small-scale processes at the individual stations. In total, GME is too dry at all depths and this trend significantly amplifies with depth. Maximal underestimation can be found on/after days with high precipitation, implying a potential mismatch between soil properties in the model and at the measurement stations. The maximum mean bias values of $-20 \%$ can be found right after the largest precipitation events between 7 and 10 August, when the near-surface soil is saturated and underestimated soil moisture values indicate an underestimated field capacity and/or an overestimated hydraulic conductivity (Krauss et al., 2010). In addition, the temporal soil moisture variability is strongly underestimated in the model, as can be seen from the variances of model and measurements shown in Table I. Even though the decrease of variability with depth is correctly simulated, the variances of mode and measurements differ by approximately a factor of 4 . On the other hand, correlation coefficients are comparatively high, at least for the upper two sensors, showing that model and measurements roughly capture the same wet and dry periods.

Figure 4 shows the mean bias between model and measurements, now for each station separately averaged over the whole COPS period. Again, the general underestimation of the soil moisture values by the model is clearly seen, as well as the increase of the bias with depth. Only at a few stations is the mean bias positive, corresponding to an overestimation by the model. Interestingly, most of these stations are situated close to each other in the southern part
Table I. Mean RMSE, correlation coefficient and variance of measured and GME-simulated soil moisture values, averaged over all stations and over the whole COPS period.

\begin{tabular}{rccrc}
\hline $\begin{array}{c}\text { Depth } \\
(\mathrm{cm})\end{array}$ & $\begin{array}{c}\text { RMSE } \\
\text { (\% by vol. })\end{array}$ & $\begin{array}{c}\text { Correlation } \\
\text { coefficient }\end{array}$ & $\sigma_{\text {meas }}^{2}$ & $\sigma_{\text {sim }}^{2}$ \\
\hline 5 & 10.8 & 0.52 & 23.3 & 6.2 \\
20 & 12.2 & 0.56 & 11.7 & 4.1 \\
50 & 17.4 & 0.38 & 7.9 & 1.8 \\
\hline
\end{tabular}

of the COPS area on the Black Forest crest and on its lee side, which could hint at a systematic and precipitation-related effect.

In addition to the stations with comparable bias values, there are stations with specifically high or low values. Low biases are for example found for station Nagold in the lee of the Black Forest, whereas a strongly increasing bias with depth is shown for Durbach-Ebersweier on the western, windward side of the Black Forest. The COPS supersite M of the ARM mobile facility (AMF, situated in the Murg valley) shows a negative bias at the surface, but positive bias at larger depth, and the highest bias values can be found for the COPS supersite $\mathrm{H}$ at Hornisgrinde, on the highest mountain top of the northern Black Forest. Figure 5 shows the comparison of modelled and measured soil moisture evolution for these four stations.

Modelled and measured soil moisture at station Nagold show very good agreement at all depth levels (Figure 5(a)). For the near-surface sensor at $5 \mathrm{~cm}$ depth, both the $2 \mathrm{~cm}$ and $6 \mathrm{~cm}$ model level were compared (dotted and solid black lines). The two model levels are very similar, so that they cannot be distinguished in Figure 5(a). On closer inspection, not all precipitation events (visible through a marked increase in soil moisture) happened simultaneously in model and measurements, but most larger wetting and drying periods are captured correctly. Furthermore, the absolute soil moisture values correspond with a mean bias of less than $2 \%$. As the COPS period was characterised by frequent synoptic-scale precipitation events, no real dry period took place until the end of August, when the lowest soil moisture values of the period were measured. Maximal values in the model were around $39 \%$, and $35 \%$ in the measurements, which is near the field capacity for the sandy loam soil texture to be found at this site (Krauss et al., 2010). The two datasets are in similar agreement for the two deeper levels. Even though the measurements show a higher variability, both datasets react to the same infiltration events from the upper levels and have the same wetting and drying characteristics, especially at $20 \mathrm{~cm}$ depth.

Similar results can be seen for the uppermost level at station Durbach (Figure 5(b)). The absolute values differ slightly more than for Nagold, but again measured and modelled soil moisture react to the same precipitation events, as seen best for a period during the second half on June. In contrast to Nagold, the two datasets for the two deeper levels do not correspond as well. Whereas the modelled values decrease with depth, the measured values at 20 and $50 \mathrm{~cm}$ depth increase and reach values around $40 \%$ (almost double the simulations), which is most probably due to the clayey silt soil texture with high water retention capacity, although the characteristics of the curves are similar. 

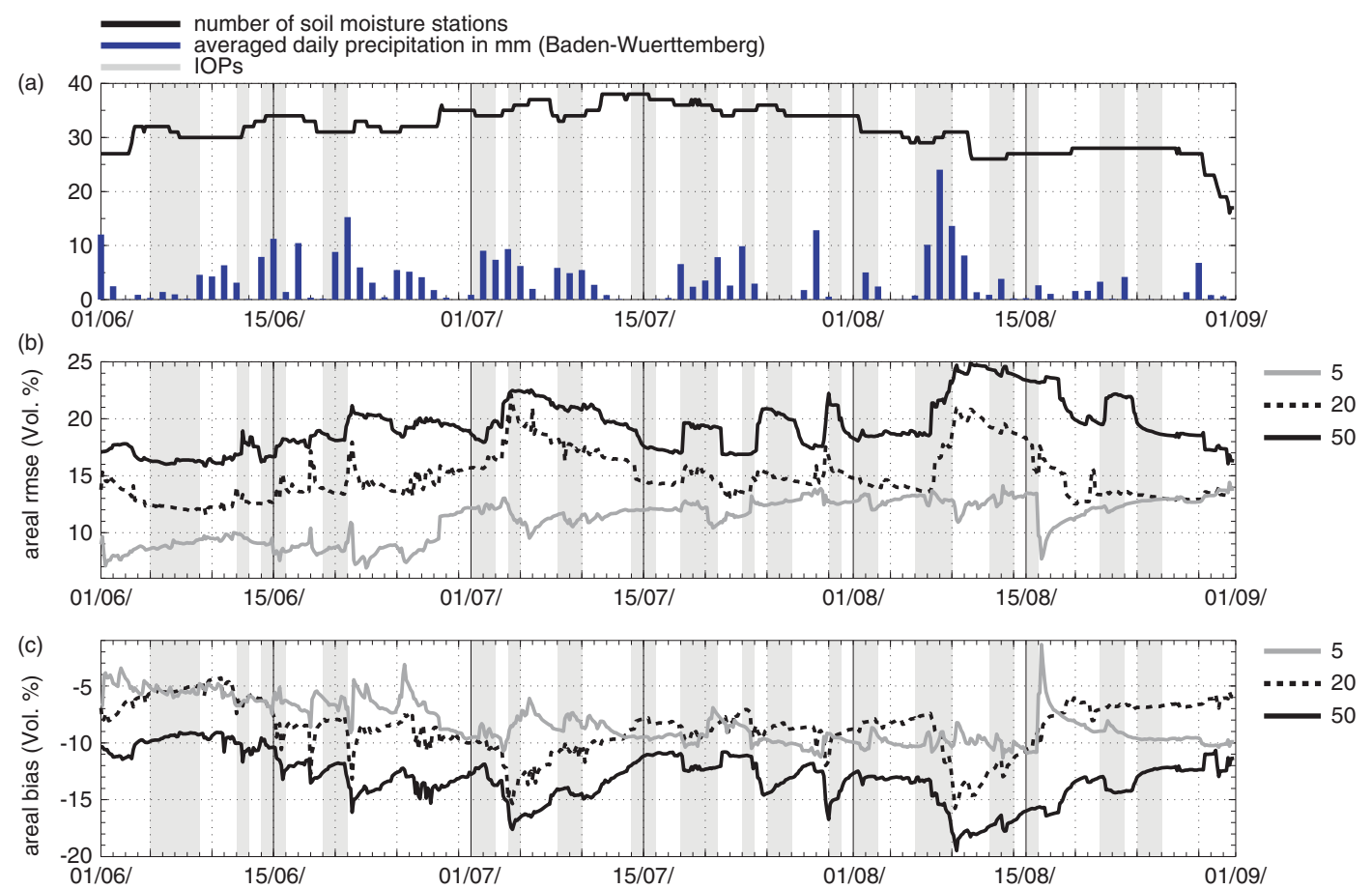

Figure 3. Temporal evolution of (a) spatially averaged daily precipitation ( $\mathrm{mm}$ ) in Baden-Württemberg (southwest Germany) taken from the precipitation network of the DWD, (b) mean root-mean-square error between soil moisture observations and GME model results, and (c) bias of GME model results for the three sensor depths averaged over the COPS domain. The solid black line in (a) denotes the number of soil moisture stations used for the analysis. Intensive Observation Periods (IOPs) are marked by grey vertical shading. This figure is available in colour online at wileyonlinelibrary.com/journal/qj
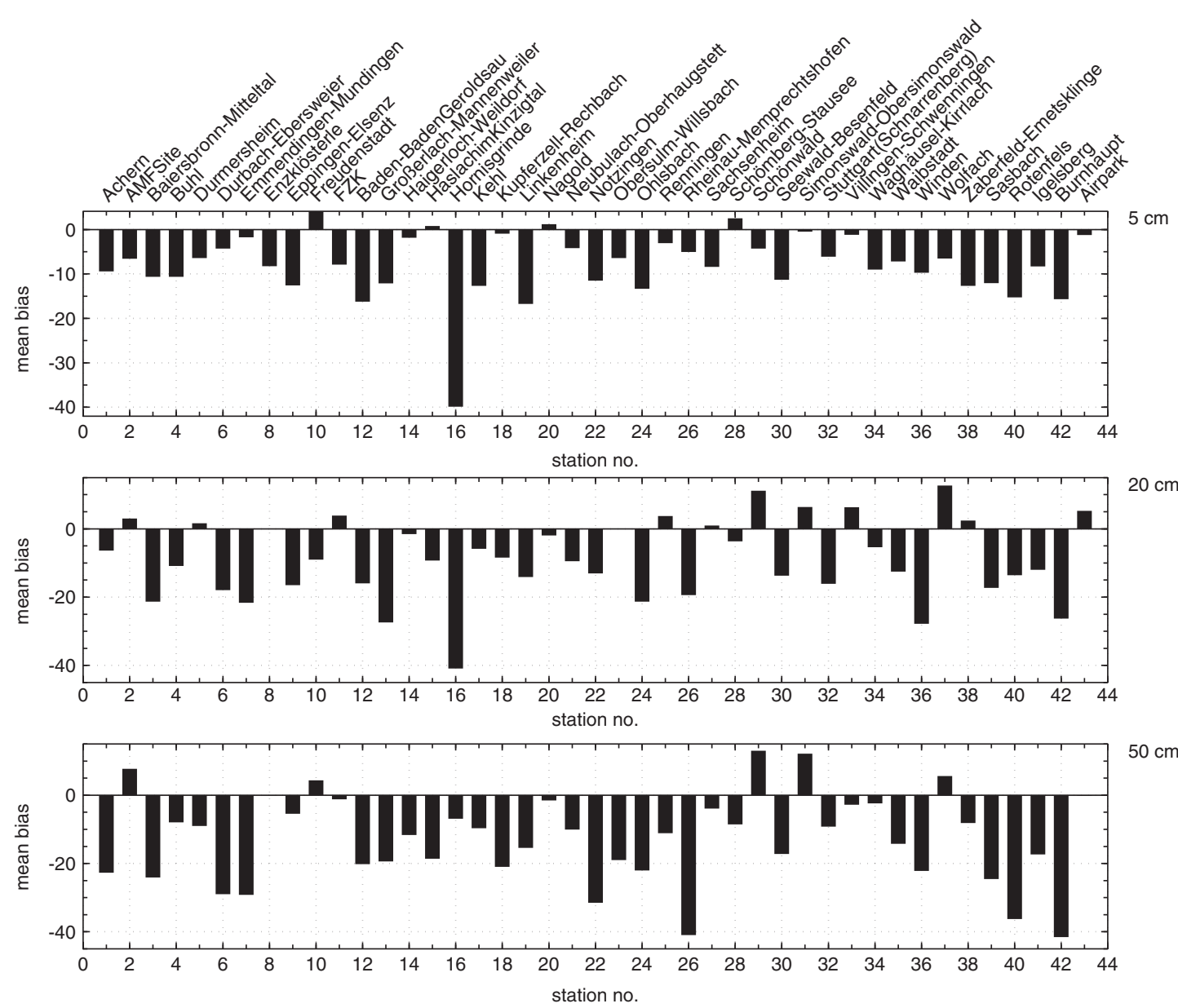

Figure 4. Mean bias between GME model and soil moisture measurement data for all stations in the network and at all depths during the COPS experiment. 

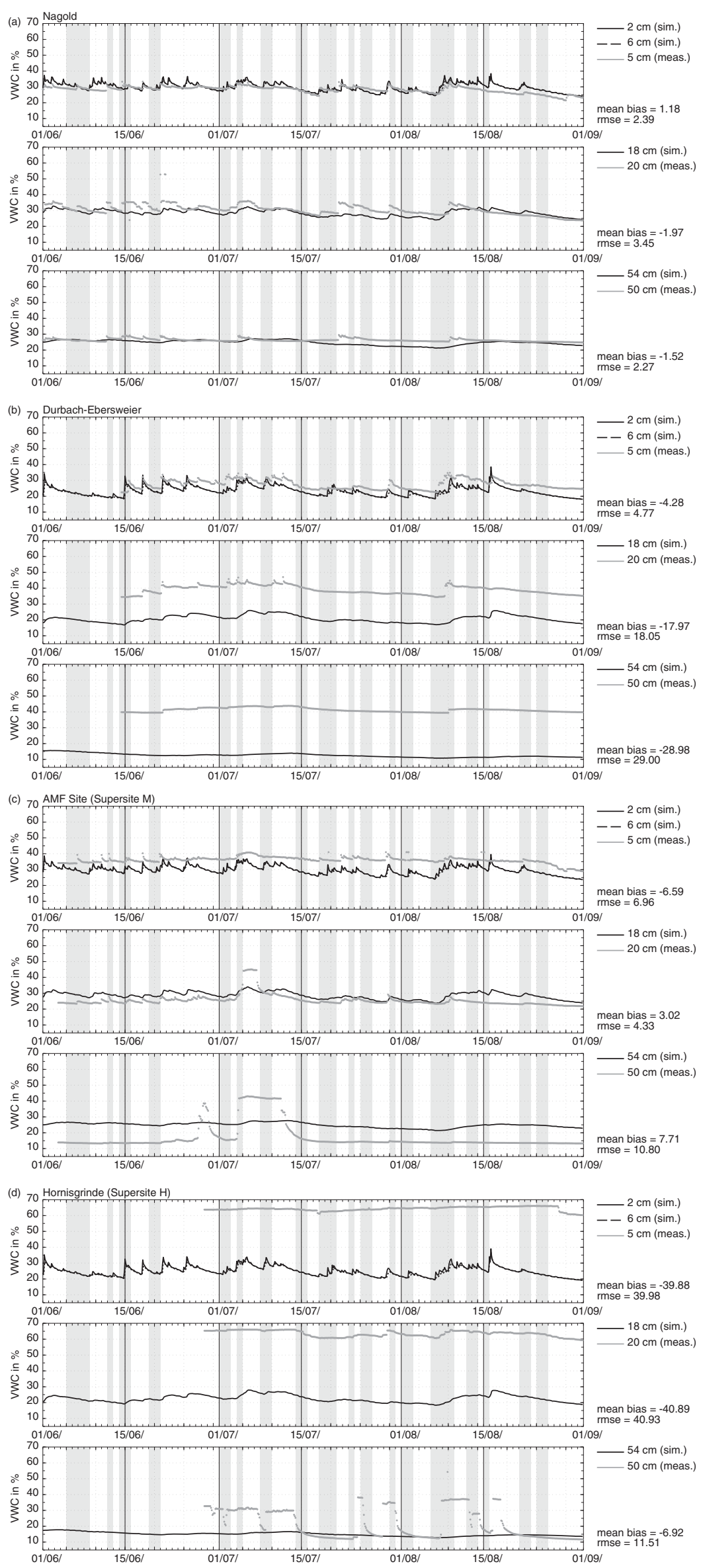

Figure 5. Comparison of modelled and measured soil moisture evolution at three different depths for the stations (a) Nagold, (b) Durbach, (c) AMF (supersite M) and (d) Hornisgrinde (supersite H). The grey shaded areas mark Intensive Observation Periods (IOPs) during COPS. 
For the AMF station (Figure 5(c)), the agreement is again comparatively good for the soil moisture in the uppermost layer with deviations between 5 and 15\%. For the sensor at $20 \mathrm{~cm}$ depth, the agreement is similar, except for a short period in the beginning of July, when the measured soil moisture increased sharply from 25 to $45 \%$. Because this event was even stronger and with longer duration at $50 \mathrm{~cm}$ depth (where also an additional sharp soil moisture increase can be seen end of June), it is not interpreted as a measurement error, but as an increase due to a raised ground water level. The station is situated in the valley bottom near to the river Murg, and a raised groundwater level would show first at larger depths, which is exactly what is observed in Figure 5(c).

Finally, Figure 5(d) shows the results for COPS supersite $\mathrm{H}$, on top of the Hornisgrinde mountain, the highest point of the northern Black Forest. As could also be seen from Figure 4, measurement and simulation show the largest bias of all stations, due to exceptionally high soil moisture values for the uppermost two sensors (between 60 and $70 \%)$. Apart from the difficulties of good sensor calibration for such high water contents, this phenomenon is due to the specific environment at Hornisgrinde, located within a upland moorland with a supersaturated surface layer during most of the year. Whereas this specific situation cannot be taken into account by the soil model used operationally, it is an important boundary condition for the analysis of surface-atmosphere exchange processes or energy balance calculations using data from this COPS supersite. Energy balance measurements during COPS showed that, due to its specific environment, neither the partitioning of the net radiation into sensible/latent heat flux nor the evolution of the near-surface equivalent potential temperature had any dependence on the soil moisture (Kalthoff et al., 2011).

Almost all the remaining stations fall into one of the four categories, as exemplified by Figure 5:

(a) good match at all levels (example Nagold, total 8 stations);

(b) good match at the surface but underestimated modelled soil moisture at greater depth (example Durbach, total 13 stations);

(c) good match at the surface but measurements show much more soil moisture variability at greater depths than the simulations (example AMF, total 15 stations); and

(d) poor match because a station-specific surface or subsurface condition could not be modelled adequately (example Hornisgrinde, total 5 stations).

The occurrence of (c) and (d) cases is not surprising, as such small-scale processes can of course not be included on the coarse GME model grid. However, for the analysis of site-specific case-studies these effects cannot be disregarded. The general underestimation of the soil moisture especially at larger depths (case (b)) may on the other hand have a more serious influence on modelled surface-atmosphere exchange processes. Its possible importance will be analysed in more detail below using high-resolution COSMO-DE simulations for individual IOP case-studies.
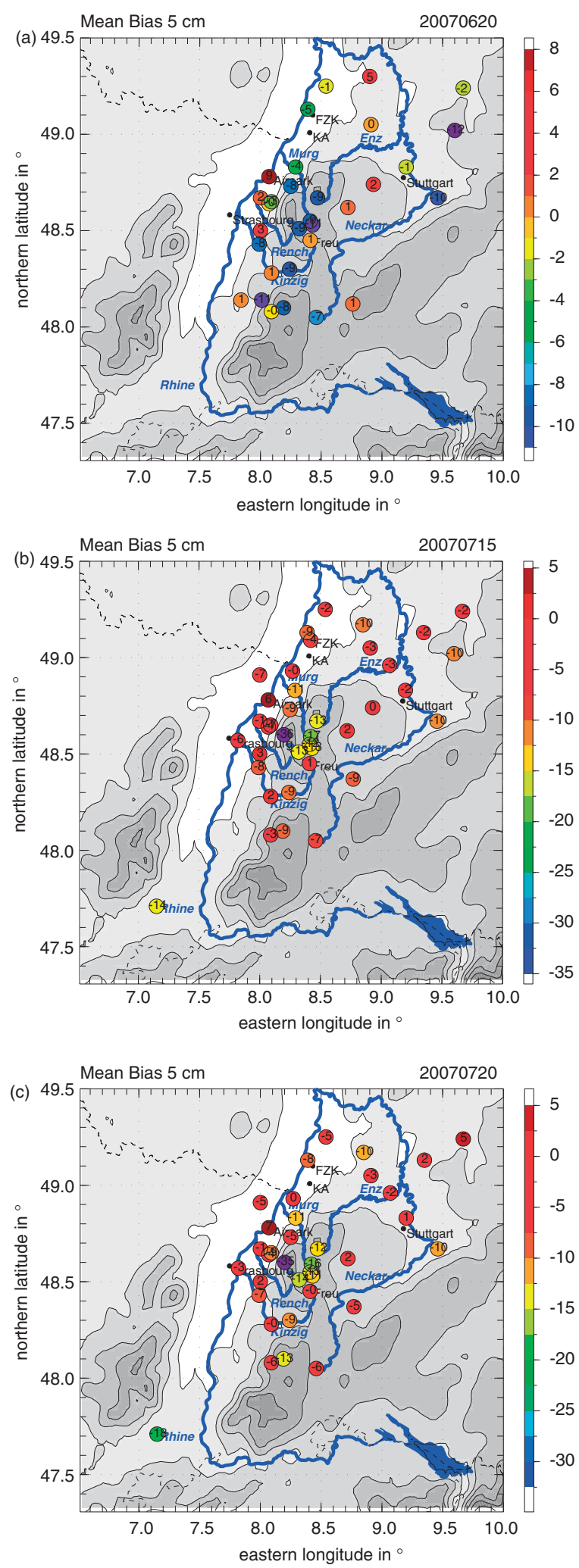

Figure 6. Spatially distributed bias between measured and modelled (COSMO-DE) near-surface soil moisture for three COPS IOPs: (a) IOP 4b, (b) IOP $8 \mathrm{~b}$ and (c) IOP 9c. Note the different colour scales for the three cases. This figure is available in colour online at wileyonlinelibrary.com/journal/qj

4.1.2. Short-term temporal and spatial variability of soil moisture

To analyse the accuracy of the soil moisture representation in a high-resolution model, simulations of individual COPS 

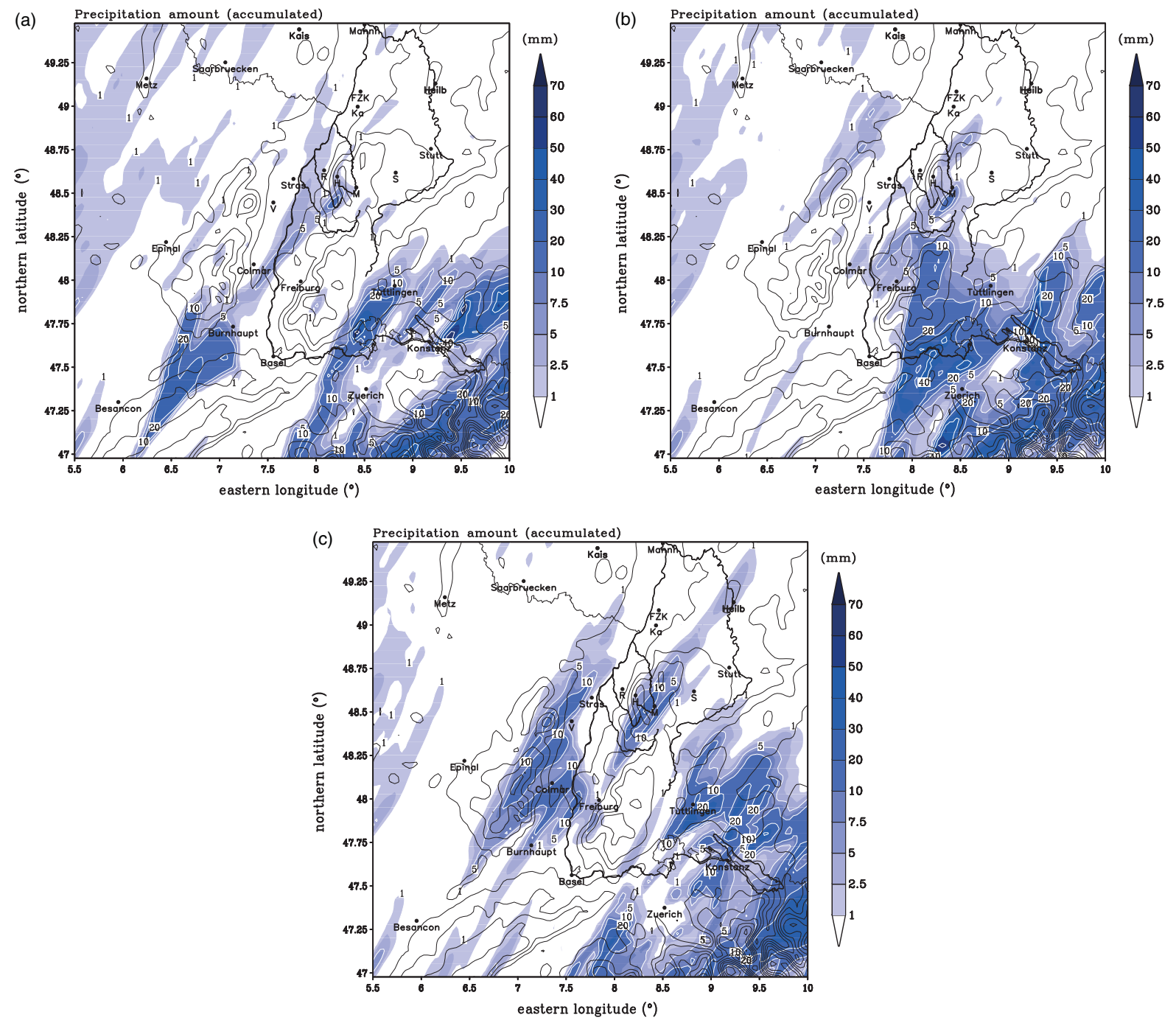

Figure 7. Accumulated daily precipitation for a simulation of COPS IOP $4 \mathrm{~b}$ (20 June 2007) with initial soil moisture content (a) increased by $25 \%$ and (c) decreased by $25 \%$. (b) shows unchanged soil moisture conditions as the reference. This figure is available in colour online at wileyonlinelibrary.com/journal/qj

IOPs were conducted with COSMO-DE and the operational TERRA subsurface model. The mean daily bias between observed and modelled near-surface soil moisture values are shown in Figure 6 for the three IOPs discussed in detail in Kottmeier et al. (2008).

As for the GME comparison shown above, there are large differences between measured and simulated soil moisture to be seen in the COSMO-DE simulations. Simulated soil moisture for the near-surface sensor is systematically too low for the two July case-studies (Figure 6(b) and (c)) in the whole COPS domain and for IOP $4 \mathrm{~b}$ (Figure 6(a)) in the Black Forest region. Generally, the bias is largest for the Black Forest region with an underestimation of soil moisture of up to $15 \%$. (The extraordinary high bias values of $35 \%$ are due to the special location of Hornisgrinde, as discussed above.)

This trend is similar for the two deeper levels (not shown), even though they exhibit more spatial variability of the bias between model and measurement.

\subsection{Influence of soil moisture on convective precipitation}

To analyse the potential impact of a general soil moisture under- or overestimation in the model, sensitivity studies using artificially increased/decreased soil moisture values were conducted for the above IOPs. For this, soil moisture values were increased/decreased by a fixed percentage over the whole model domain. Data analyses include the difference in simulated precipitation values as well as a closer inspection of the energy balance and atmospheric variables known to be important for the initiation of convection and corresponding convective precipitation. As an approximate upper bound of biases between simulated and observed soil moisture, the initial soil moisture values were increased and decreased by $25 \%$.

\subsubsection{Precipitation}

Figure 7 shows the resulting daily accumulated precipitation values for the example of IOP $4 \mathrm{~b}$ from 20 June 2007. This IOP was characterised by widespread convection in different parts of the COPS area caused by

(i) initiation from the surface (southern and northern part),

(ii) triggering by orographic effects (but only weak thermally driven wind systems), and 

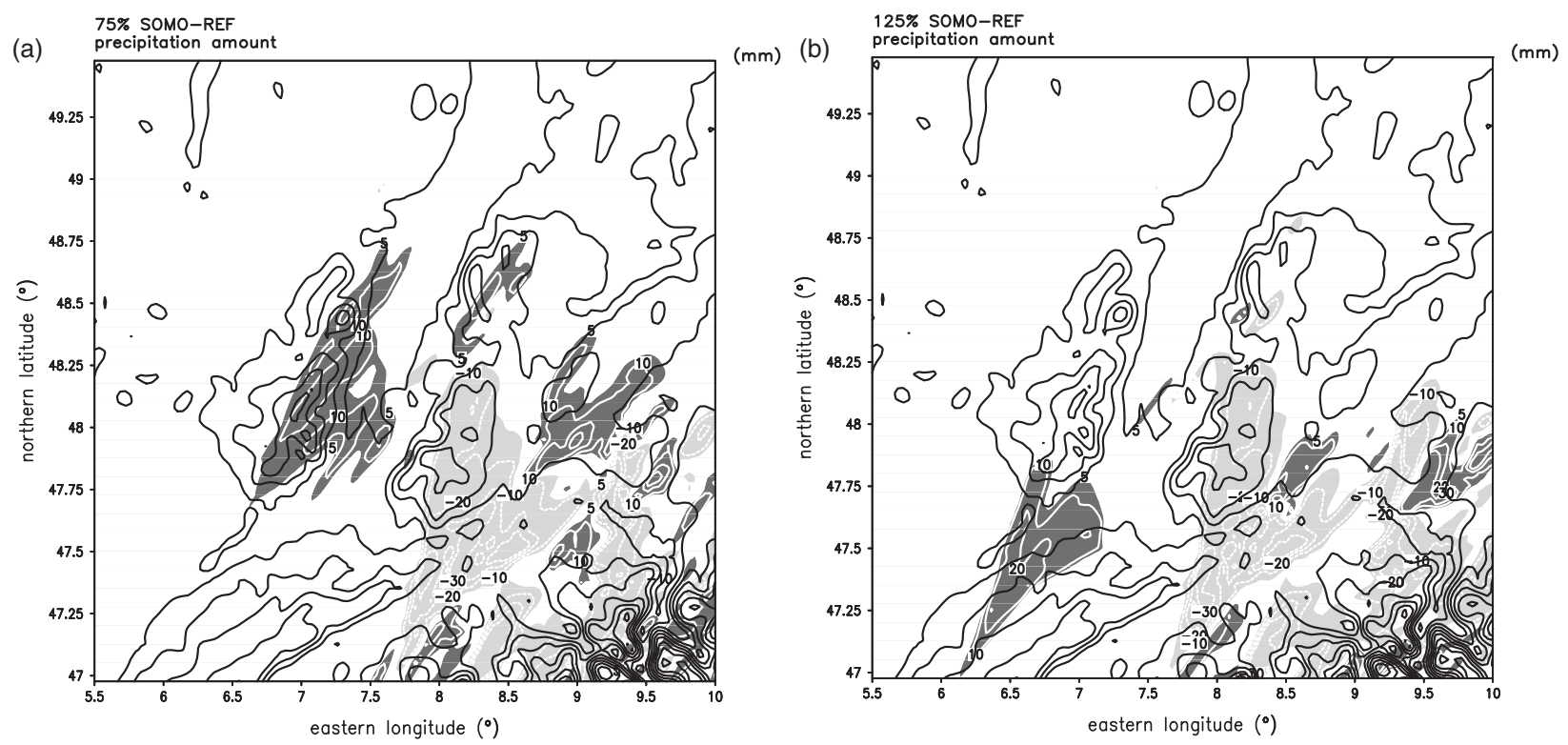

Figure 8. Plots of precipitation difference taken from Figure 7. (a) shows Figure 7(c) minus 7(b), and (b) shows Figure 7(a) minus 7(b). Positive and negative values are shown in dark and light grey, respectively.

(iii) mid-tropospheric lifting, mainly in the southwestern part (Kottmeier et al., 2008).

Precipitation occurred mainly along and on the leeside of the mountain ranges of the Vosges and Black Forest mountains as well as in the southeastern part, while the Rhine valley was free of deep convective clouds.

In good agreement with the observed precipitation, accumulated precipitation in the reference simulation (Figure 7(b)) is highest in the southeastern part of the COPS area and over the Black Forest. Almost no precipitation is found in the Rhine valley and in the northeastern part of the COPS area. In contrast, for reduced initial soil moisture conditions, precipitation is increased on the lee side of the Vosges mountains and in the Rhine valley and decreased over the southern Black Forest, whereas it is decreased over the whole Black Forest for increased soil moisture conditions (Figures 8(a) and (b)). Even though the moisture content in the PBL was predominantly influenced by the large-scale flow on this day, simulations show that different soil moisture conditions may influence convection through modifying the surface temperature and hence the potential for reaching the convective temperature, one of the possible trigger mechanisms for CI.

The above result for the Vosges mountains and the Rhine valley is in good agreement with other high-resolution studies over complex terrain (Hohenegger et al., 2009), where reduced soil moisture did tend to increase CI, as the convective temperature was reached more easily for drier soil surfaces. The fact that both the reduced and increased soil moisture runs result in a decrease of precipitation over the Black Forest possibly suggests that the reference soil moisture field of that day acts as a kind of maximum threshold value, where the convective temperature is just reached and convection was initiated over the Black Forest. A further increase inhibited convective activity due to a lack of thermal forcing, whereas a decrease led to a reduction of CAPE, which similarly inhibited convective activity.

In contrast, a positive effect was observed for the increased soil moisture run of IOP 9c, with a precipitation increase by up to $50 \%$ outside the Black Forest (Figure 9(c)). Here, convection was initiated along a convergence line, with a reduced sensitivity to thermal forcing, but an enhancement of convection through the additional availability of moisture (Kottmeier et al., 2008). A reduction of soil moisture led to a small precipitation increase over the Black Forest (Figure 9(b)), where no precipitation was observed in the control run (Figure 9(a)), due to the higher thermal forcing in accordance to the results for IOP $4 \mathrm{~b}$.

Almost no precipitation was simulated for IOP $8 \mathrm{~b}$ (not shown) which is consistent with observations, since only an isolated cell was detected over the Black Forest (Kalthoff et al., 2009). Due to consistently high convective inhibition (CIN) values, no CI was simulated in all three sensitivity runs, even though a large sensitivity of the turbulent fluxes, the near-surface temperature and moisture on changed soil moisture was observed (Barthlott et al., 2010, and next section).

\subsubsection{Energy balance and convective indices}

Figure 10 shows the various components of the energy balance as well as some convective indices for the case of IOP 8b (15 July 2007), where locally initiated convection took place over the Black Forest (Kottmeier et al., 2008; Kalthoff et al., 2009; Barthlott et al., 2010). On this day the warm but very dry air mass did not allow early and widespread convection to develop.

Generally, the amount of net radiation available for transformation into sensible and latent heat flux is larger for high than for low soil moisture conditions, as soil moisture reduces outgoing short- and long-wave radiation via albedo and surface temperature, respectively. However, for IOP $8 \mathrm{~b}$ the impact of a reduced or increased soil moisture on the radiation budget is low (Figure 10(a)). This is in good accordance with energy balance measurements during the COPS period, where the dependence of the albedo on soil moisture was found to be weak (Kalthoff et al., 2011), probably because soil moisture variation was too weak during COPS. On the other hand, all other model variables shown in Figure 10 with the exception of CIN 

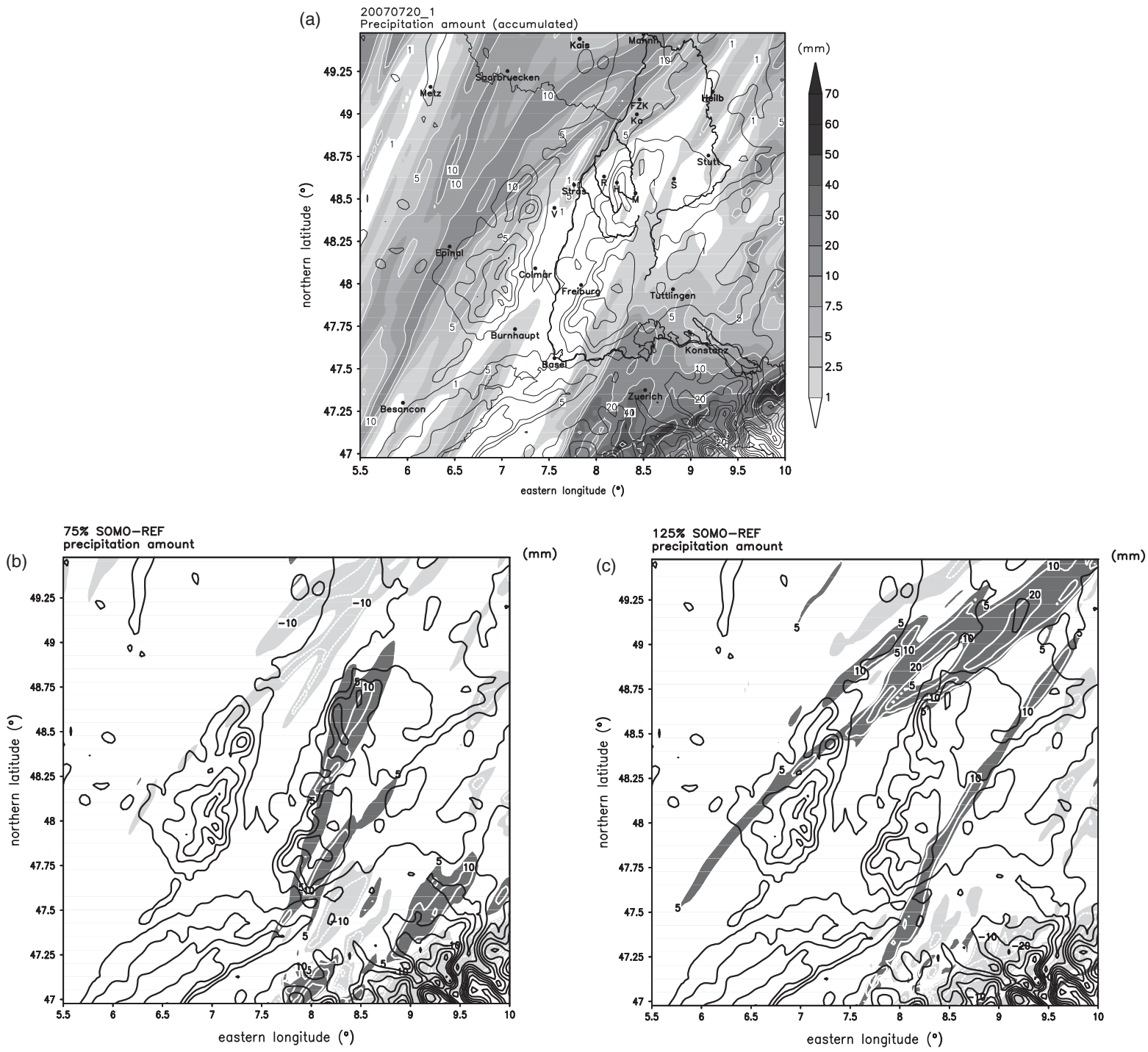

Figure 9. (a) Accumulated daily precipitation for the reference simulation of COPS IOP 9c (20 July 2007) with unchanged soil moisture conditions, and precipitation difference plots for (b) 25\% decreased and (c) 25\% increased soil moisture minus the reference. Positive and negative values in (b) and (c) are shown in dark and light grey, respectively.

(Figure 10(f)) show a systematic response, that is they show consistently increasing/decreasing values for either increasing or decreasing soil moisture conditions. A reduced soil moisture would therefore lead to a strongly increased Bowen ratio, a reduced CAPE and an increased LI. The decreasing effect on CAPE is strongest for the Black Forest, where a $25 \%$ reduction in soil moisture leads to a reduction of maximal CAPE values from 1500 to $700 \mathrm{~J} \mathrm{~kg}^{-1}$. This effect is much smaller for the Rhine valley (reduction from 600 to $400 \mathrm{~J} \mathrm{~kg}^{-1}$ ).

As a further potential influence of soil moisture, the timing of CI at the surface is dependent on how fast the surface temperature can reach the convective temperature, both being dependent on the near-surface soil moisture. Figure 11 shows the influence of soil moisture on temperature, equivalent potential temperature and convective temperature at four COPS stations and for several IOPs. Heselbach (= AMF site) is a station within the Black Forest, whereas FZK and Achern are located in the northern and southern parts of the Rhine valley, respectively. For IOP $8 \mathrm{~b}$, the results show that a reduced soil moisture would lead to an increase in the convective temperature of around $0.6 \mathrm{~K}$ (AMF) and $0.7 \mathrm{~K}$ (Achern), and to an increase of $2 \mathrm{~m}$ temperature of around $1 \mathrm{~K}$ for both sites. An increased soil moisture would lead to a decrease in convective temperature by $0.8 \mathrm{~K}$ (AMF) and $0.6 \mathrm{~K}$ (Achern), and a decrease in $2 \mathrm{~m}$ temperature by $0.8 \mathrm{~K}$ (AMF) and $0.7 \mathrm{~K}$ (Achern).

Kottmeier et al. (2008) found that the maximum $2 \mathrm{~m}$ temperature of $33^{\circ} \mathrm{C}$ on that day was a little less than the necessary convective temperature of $34^{\circ} \mathrm{C}$ in the northern Rhine valley near Karlsruhe. Thus, CAPE could not be released by buoyancy in this case. The results from Figure 11 indicate that the net influence of soil moisture on the surface temperature and convective temperature is systematic but small (less than $0.5 \mathrm{~K}$ ), so that for IOP $8 \mathrm{~b}$ no improvement of the modelled precipitation could be shown by using a more realistic soil moisture initialisation. However, combined with a significant difference in the amount of CAPE, especially over the Black Forest, there is a clear benefit of using improved soil moisture initialisation.

A general analysis of the results of the sensitivity experiments for several COPS IOPs showed that wet soil conditions in the model indeed lead to moister and cooler boundary layers as well as lowered lifting condensation levels and levels of free convection, facilitating the development of deep convection (not shown). In particular, the interplay 

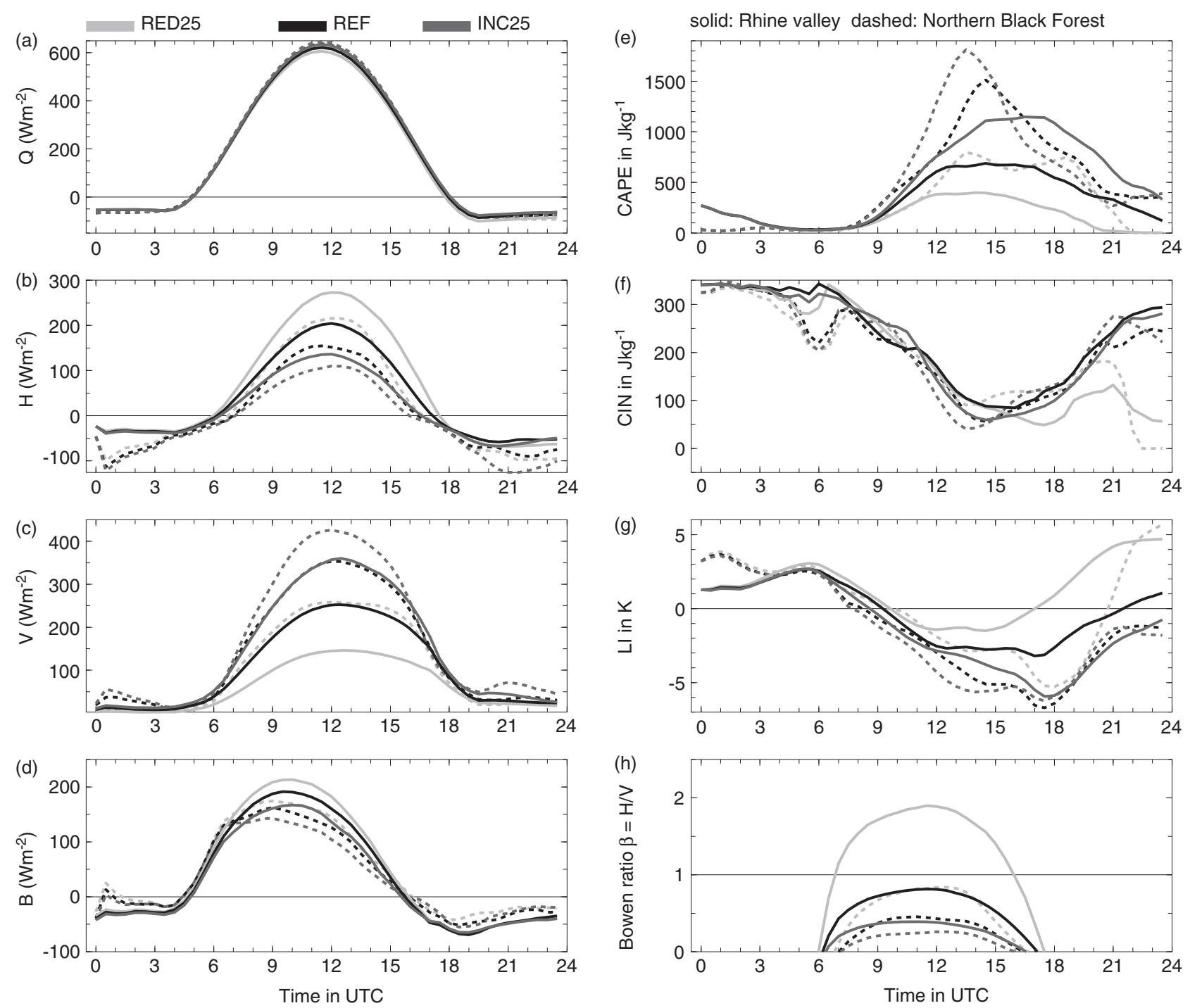

Figure 10. Areal mean values for the energy balance and convective indices for the simulation of IOP 8b (15 July 2007 ) with increased and decreased initial soil moisture values. Mean values for the Rhine valley (solid) and northern Black Forest (dashed) regions are shown. (a) Net radiation, (b) sensible het flux, (c) latent heat flux, (d) ground heat flux, (e) CAPE, (f) convective inhibition (CIN), (g) lifted index (LI) and (h) Bowen ratio.

between CAPE, which may depend strongly on surface fluxes, and CIN, being more dependent on upper-level processes, plays a major role in the impact of soil moisture in complex terrain (see also Kalthoff et al., 2011). However, for most mid-tropospheric forcing cases of convection, the soil moisture plays no (or only a very minor) role, because the humidity in the PBL (which strongly influences the above-mentioned variables) is advected from upstream and does not depend on the soil characteristics. This was the case for about 21 IOP days during COPS, as opposed to 14 days with (at least partly) locally initiated convection (Kottmeier et al., 2008).

\section{Discussion and summary}

We presented a comparison of modelled and observed soil moisture values in the near subsurface with the aim of analysing systematic discrepancies of soil moisture variability and their potential impacts on the simulation of convective processes over complex terrain. The soil moisture dataset consists of data from a newly installed soil moisture monitoring network in southwest Germany. These data were compared with operational long-term analysis data from the GME model of the DWD as well as with case-study simulations with the high-resolution nonhydrostatic model COSMO-DE (2.8 km resolution). The large-scale GME model data were used because, in contrast to the operational non-hydrostatic COSMO-EU, in GME no assimilation scheme is used that adjusts soil moisture such that errors in near-surface temperature are minimised.

To analyse the potential impact of systematic soil moisture errors in the model, sensitivity simulations with increased and decreased soil moisture were conducted for three casestudies from the Convective and Orographically-induced Precipitation Study (COPS).

Key results from this study using this new (and for the region unique) soil moisture dataset are as follows:

- Large differences between GME-simulated and observed soil moisture values can be observed. The model is generally too dry at all depths and this trend amplified with depth. Mean bias values are between $-5 \%$ and $-10 \%$ by volume at the surface and maximum discrepancies are around $-20 \%$. In addition, temporal soil moisture variability is underestimated in the model. 


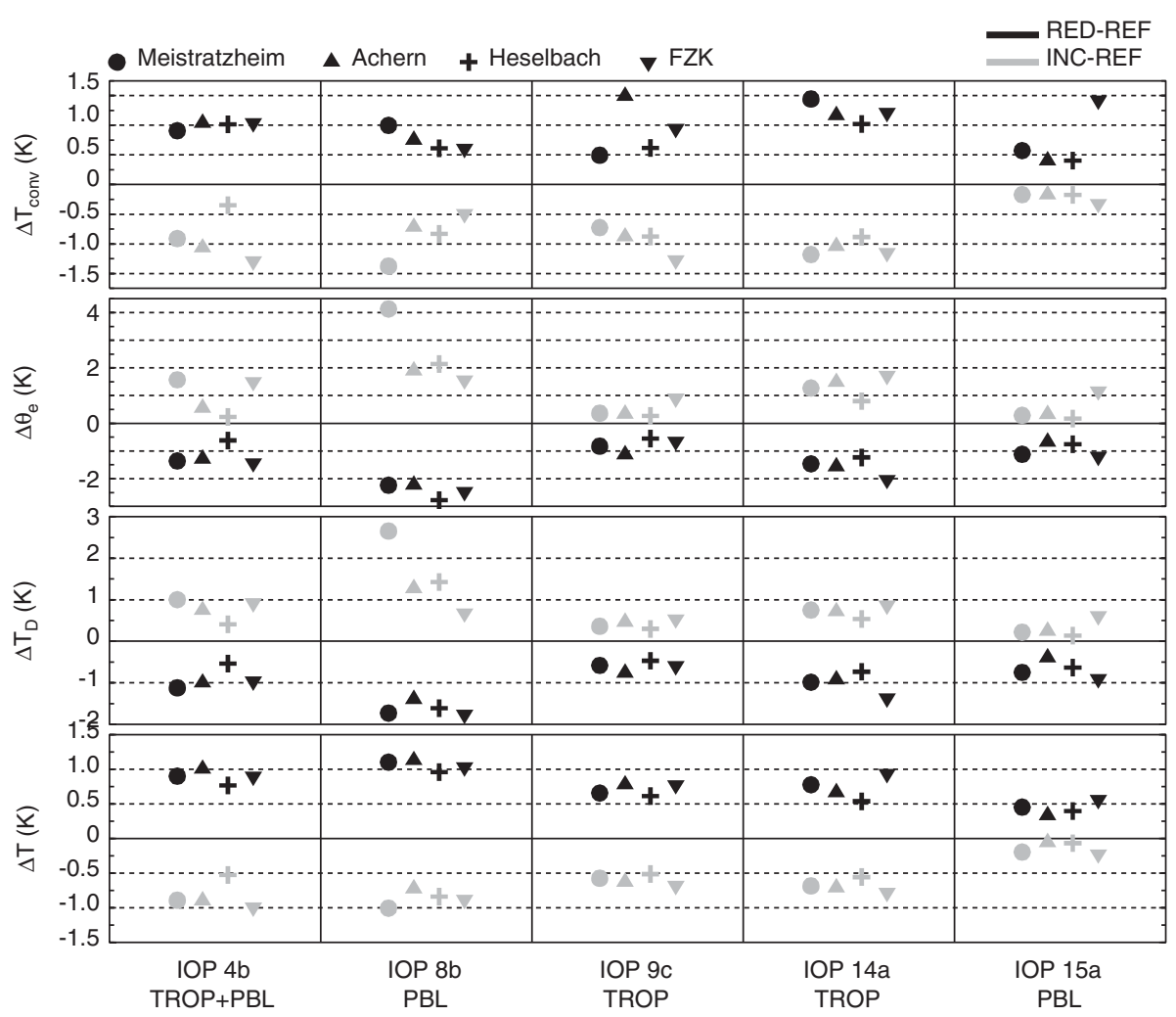

Figure 11. Temperature differences from reference values arising from increased (light points) and decreased (dark points) soil moisture: (a) convective temperature, (b) equivalent potential temperature, (c) dew point temperature, and (d) $2 \mathrm{~m}$ temperature for four COPS stations with energy balance data and for five IOPs.

- Detailed analyses of simulation minus observation discrepancies for individual stations revealed four distinct groups of stations: (a) those with a good match at all levels (8 stations), (b) those with a good match at the surface, but underestimated soil moisture at greater depth (13 stations), (c) those with a good match at the surface, but higher soil moisture variability in the measurements at greater depth (15 stations) and (d) those with a poor match, because a site-specific (sub-)surface condition could not be modelled adequately (5 stations).

- High-resolution modelling of specific days such as the COPS IOP 8b with COSMO-DE also showed a mean bias towards too dry soil conditions, especially on the windward side and on the crest of the Black Forest, where precipitation is maximal. Generally, soil moisture values in COSMO-DE simulations were too low with the largest biases near the surface and for the Black Forest region (up to 15\% underestimation).

- The influence of this bias on simulated precipitation is non-trivial and potentially large, and depends on the specifics of the analysed case-study. For example, sensitivity simulations for COPS IOP $4 \mathrm{~b}$ with increased soil moisture showed decreased precipitation over the whole Black Forest, whereas decreased soil moisture simulations showed increased precipitation in the Rhine valley and the Vosges mountains and decreased precipitation in the southern part of the COPS region. In contrast, the opposite effect was observed for IOP 9c, where convection was initiated along a convergence line. There, precipitation outside the Black Forest was enhanced for increased soil moisture values through the additional availability of moisture.

- The simulations presented in this study demonstrate that soil moisture has a considerable impact on convection-related parameters in complex and heterogeneous terrain. Sensitivity experiments showed significant dependences of convection-related parameters such as CAPE, Bowen ratio and surface temperature on soil moisture, but no systematic influence on convective precipitation due to a complex and regionally different interplay with convection inhibiting factors, such as CIN.

Following Koster et al. (2009), we point out that the value of modelled soil moisture in operational weather prediction models lies not in its absolute magnitude but in its time variations, as soil moisture is often treated as an adjusting variable to produce realistic near-surface temperatures (as e.g. in COSMO-DE). Similarly, in GME, where no adjustment is performed, small-scale and sitespecific processes cannot be modelled on the coarse GME grid. The site-specific discrepancies between GME modelled and observed soil moisture found in this study are therefore not surprising. Koster et al. (2009) emphasised that the existence of in situ data does not guarantee their usefulness as measurements are highly localised, and differences in soil properties can cause important differences in the mean and variance of soil moisture, even over small distances.

However, the general underestimation of soil moisture may have a significant influence on modelled surface-atmosphere exchange processes, as was shown also in a number of previous studies (e.g. Georgescu et al., 2003; Jones and Brunsell, 2009). On the other hand, observed land-surface exchange processes during COPS were studied in detail in 
a companion paper using soil moisture, turbulence, and energy balance data (Kalthoff et al., 2011). There it was found that latent heat fluxes and conditions in the convective boundary layer were barely dependent on soil moisture in the mountainous regions of the Black Forest, but weakly dependent in the Rhine valley. Assuming that large-scale advection affected the whole COPS domain uniformly, the results indicate that contributions from mesoscale advection and entrainment processes were more important over complex terrain during COPS. In contrast to the model results, Kalthoff et al. (2011) found no significant correlations between the convection-related parameters (such as CAPE and CIN) and the soil moisture measurements during the COPS period, due to the observed weak correlation between soil moisture and the surface fluxes and between the surface fluxes and the boundary-layer conditions.

This observed lack of sensitivity of fluxes to soil moisture over the Black Forest contrasts with the model behaviour. This suggest that the model behaviour overestimates the influence of soil moisture which may be caused by an inadequate description of soil textures and/or land-surface exchange processes. It has to be kept in mind that IOPs during COPS were predominantly performed during warm and humid conditions and that the COPS summer was wetter than climatology (Wernli et al., 2010; Wulfmeyer et al., 2011), which may also have influenced the reduced dependence of the PBL on energy supply from the surface.

The considerable sensitivity of precipitation to soil moisture in complex terrain as shown in the model examples of this study demonstrates the particular importance of accurate initial soil moisture fields in NWP models. A potential benefit of a more realistic representation of soil moisture in those models could be an improvement of quantitative precipitation forecasts, a hypothesis which would have to be tested using a series of sensitivity experiments and observational evidence over a longer time span than the COPS period. This has not been addressed so far and would have been beyond the scope of this contribution.

Future work will therefore include model simulations that are initialised with observed soil moisture fields to evaluate the potential of improvement of the simulation of CI by using operational soil moisture data.

\section{Acknowledgements}

The authors wish to thank the Deutsche Forschungsgemeinschaft (DFG) for funding the Priority Programme SPP 1167 in which this study as well as the field campaign COPS were embedded. We also thank the Deutscher Wetterdienst (DWD) for providing the COSMO model code as well as initial and boundary data. Permission for the installation of the soil moisture stations was kindly granted by the DWD and Landesanstalt für Umwelt, Messungen und Naturschutz Baden-Württemberg, Germany (LUBW), who also provided the corresponding precipitation data. We are grateful for the constructive comments of two anonymous reviewers.

\section{References}

Alonge CJ, Mohr KI, Tao WK. 2007. Numerical studies of wet versus dry soil regimes in the West African Sahel. J. Hydrometeorol. 8: 102-116.

Baldi M, Dalu GA, Pielke RA. 2008. Vertical velocities and available potential energy generated by landscape variability - Theory. J. Appl. Meteorol. Climatol. 47: 397-410.
Barthlott C, Schipper JW, Kalthoff N, Adler B, Kottmeier C, Blyth A, Mobbs S. 2010. Model representation of boundary-layer convergence triggering deep convection over complex terrain: A case study from COPS. Atmos. Res. 95: 172-185.

Brunsell NA, Gillies RR. 2003. Scale issues in land-atmosphere interactions: Implications for remote sensing of the surface energy balance. Agric. Forest Meteorol. 117: 203-221. DOI: 10.1016/S01681923(03)00064-9.

Chen F, Avissar R. 1994. The impact of land-surface heterogeneity on mesoscale heat fluxes. J. Appl. Meteorol. 33: 1323-1340.

Clark DB, Taylor CM, Thorpe AJ. 2004. Feedback between the land surface and rainfall at convective length scales. J. Hydrometeorol. 5: 625-639.

Dai A, Trenberth KE, Karl TR. 1999. Effects of clouds, soil moisture, precipitation, and water vapor on diurnal temperature range. J. Climate 12: 2451-2473.

Doms G, Förstner J, Heise E, Herzog H-J, Raschendorfer M, Reinhardt T, Ritter B, Schrodin R, Schulz J-P, Vogel G. 2007. 'A description of the nonhydrostatic regional model LM, Part II: Physical parameterization'. Available at http://www.cosmo-model.org.

Fischer E, Seneviratne S, Vidale P, Lüthi D, Schär C. 2007. Soil moisture atmosphere interactions during the 2003 European summer heat wave. J. Climate 20: 5081-5099.

Gantner L, Kalthoff N. 2010. Sensitivity of a modelled life cycle of a mesoscale convective system to soil conditions over West Africa. Q. J. R. Meteorol. Soc. 136: 471-482.

Georgescu M, Weaver CP, Avissar R, Walko RL, Gonzalo MM. 2003. Sensitivity of model-simulated summertime precipitation over the Mississippi River basin to the spatial distribution of initial soil moisture. J. Geophys. Res. 108: DOI: 10.1029/2002JD003107.

Heise E, Lange M, Ritter B, Schrodin R. 2003. 'Improvement and validation of the multi-layer soil model'. COSMO Newsletter 3: 198-203. Available at http://www.cosmo-model.org.

Hohenegger C, Brockhaus P, Bretherton CS, Schär C. 2009. The soil moisture-precipitation feedback in simulations with explicit and parametrized convection. J. Climate 22: 5003-5020.

Jones AR, Brunsell NA. 2009. A scaling analysis of soil moisture - precipitation interactions in a regional climate model. Theoret. Appl. Climatol. 98: 221-235.

Kalthoff N, Adler B, Barthlott C, Corsmeier U, Mobbs S, Crewell S, Träumner K, Kottmeier C, Wieser A, Smith V. 2009. The impact of convergence zones on the initiation of deep convection: A case study from COPS. Atmos. Res. 93: 680-694.

Kalthoff N, Kohler M, Barthlott C, Adler B, Mobbs SD, Corsmeier U, Träumner K, Foken T, Eigenmann R, Krauss L, Khodayar S, Di Girolamo P. 2011. The dependance of convection-related parameters on surface and boundary-layer conditions over complex terrain. Q. J. R. Meteorol. Soc. 137(S1): 70-80, DOI: 10.1002/qj.686.

Kerr YH. 2007. Soil moisture from space: Where are we? Hydrogeol. J. 15: $117-120$.

Kerr YH, Waldteufel P, Wigneron J-P, Martinuzzi J-M, Font J, Berger M. 2001. Soil moisture retrieval from space: The Soil Moisture and Ocean Salinity (SMOS) mission. IEEE Trans. Geosci. Remote Sensing 39: 1729-1735.

Kohler M, Kalthoff N, Kottmeier C. 2010. The impact of soil moisture modifications on CBL characteristics in West Africa: A case-study from the AMMA campaign. Q. J. R. Meteorol. Soc. 136: 442-455.

Koster RD, Suarez MJ, Heiser M. 2000. Variance and predictability of precipitation at seasonal-to-interannual timescales. J. Hydrol. 1: 26-46.

Koster RD, Dirmeyer PA, Guo Z, Bonan G, Chan E, Cox P, Gordon CT, Kanae S, Kowalczyk E, Lawrence D, Liu P, Lu CH, Malyshev S, McAvaney B, Mitchell K, Mocko D, Oki T, Oleson K, Pitman A, Sud TC, Taylor CM, Verseghy D, Vasic R, Xue Y, Yamada T. 2004. Regions of strong coupling between soil moisture and precipitation. Science 305: 1138-1140.

Koster RD, Guo Z, Yang R, Dirmeyer PA, Mitchell K, Puma MJ. 2009. On the nature of soil moisture in land surface models. J. Climate 22: 4322-4335.

Koster RD, Mahanama SPP, Yamada TJ, Balsamo G, Bergand AA, Boisserie M, Dirmeyer PA, Doblas-Reyes FJ, Drewitt G, Gordon CT, Guo Z, Jeong JH, Lawrence DM, Lee WS, Li Z, Luo L, Malyshev S, Merryfield WJ, Seneviratne SI, Stanelle T, van den Hurk BJJM, Vitart F, Wood EF. 2010. Contribution of land surface initialization to subseasonal forecast skill: First results from a multi-model experiment. Geophys. Res. Lett. 37: 4322-4335. DOI: 10.1029/2009GL041677.

Kottmeier C, Kalthoff N, Barthlott C, Corsmeier U, Van Baelen J, 
Behrendt A, Behrendt R, Blyth A, Coulter R, Crewell S, Di Girolamo P, Dorninger M, Flamant C, Foken T, Hagen M, Hauck C, Höller H, Konow H, Kunz M, Mahlke H, Mobbs S, Richard E, Steinacker R, Weckwerth T, Wieser A, Wulfmeyer V. 2008. Mechanisms initiating deep convection over complex terrain during COPS Meteorol. Z. 17: 931-948.

Krauss L, Hauck C, Kottmeier C. 2010. Spatio-temporal soil moisture variability in Southwest Germany observed with a new monitoring network within the COPS domain. Meteorol. Z. 19(6): 523-537, DOI 10.1127/0941-2948/2010/0486.

Majewski D, Liermann D, Prohl P, Ritter B, Buchhold M, Hanisch T, Paul G, Wergen W. 2002. The operational global icosahedral-hexagonal gridpoint model GME: Description and highresolution tests. Mon. Weather Rev. 130: 319-338.

Naeimi V, Scipal K, Bartalis Z, Hasenauer S, Wagner W. 2009. An improved soil moisture retrieval algorithm for ERS and METOP scatterometer observations. IEEE Trans. Geosci. Remote Sensing 47: 1999-2013.

Pal JS, Eltahir EAB. 2001. Pathways relating soil moisture conditions to future summer rainfall within a model of the land-atmosphere system. J. Climate 14: 1227-1242.

Pan Z, Talke E, Segal M, Turner R. 1996. Influences of model parameterization schemes on the response of rainfall to soil moisture in the central United States. Mon. Weather Rev. 124: $1786-1802$.

Schädler G. 1990. Triggering of atmospheric circulations by moisture inhomogeneities of the Earth's surface. Boundary-Layer Meteorol. 51: $1-29$.

Schär C, Lüthi D, Beyerle U. 1999. The soil-precipitation feedback: A process study with a regional climate model. J. Climate $\mathbf{1 2}$ $722-741$.

Schättler U. 2009. 'A description of the nonhydrostatic regional COSMOModel Part V. Preprocessing: Initial and boundary data for the COSMO-Model'. Available at http://www.cosmo-model.org.

Schättler U, Doms G, Schraff C. 2008. 'A description of the nonhydrostatic regional COSMO-Model, Part VII: User's Guide'. Available at http://www.cosmo-model.org.

Seneviratne S, Lüthi D, Litschi M, Schär C. 2006. Land - atmosphere coupling and climate change in Europe. Nature 443: 205-209. DOI: 10.1038/nature05095.

Taylor CM, Ellis RJ. 2006. Satellite detection of soil moisture impacts on convection at the mesoscale. Geophys. Res. Lett. 33: L03404, DOI 10.1029/2005GL025252.

Taylor CM, Lebel T. 1998. Observational evidence of persistent convective-scale rainfall patterns. Mon. Weather Rev. 126: 1597-1607.
Taylor CM, Parker DJ, Harris PP. 2007. An observational case study of mesoscale atmospheric circulations induced by soil moisture. Geophys. Res. Lett. 34: L15801, DOI: 10.1029/2007GL030572.

Ulanski SL, Garstang M. 1978. The role of surface divergence and vorticity in the life cycle of convective rainfall. Part I: Observations and analysis. J. Atmos. Sci. 35: 1047-1062.

Vitart F, Buizza R, Balmaseda MA, Balsamo G, Bidlot JR, Bonet A, Fuentes M, Hofstadler A, Molteni F, Palmer TN. 2008. The new VAREPS monthly forecasting system: A first step towards seamless prediction. Q. J. R. Meteorol. Soc. 134: 1789-1799.

Wagner W, Verhoest N, Ludwig R, Tedesco M. 2009. Remote sensing in hydrological sciences. Hydrol. Earth Syst. Sci. 13: 813-817.

Warrach-Sagi K, Wulfmeyer V, Grasselt R, Ament F, Simmer C. 2008. Streamflow simulations reveal the impact of the soil parameterization. Meteorol. Z. 17: 751-762.

Weckwerth TM. 2000. The effect of small-scale moisture variability on thunderstorm initiation. Mon. Weather Rev. 128: 4017-4030.

Wernli H, Pfahl S, Trentmann J, Zimmer M. 2010. How representative were the meteorological conditions during the COPS field experiment in summer 2007? Meteorol. Z. 19: 619-630.

Wilson JW, Schreiber WE. 1986. Initiation of convective storms at radarobserved boundary-layer convergence lines. Mon. Weather Rev. 114: $2516-2536$.

Wulfmeyer V, Behrendt A, Bauer H-S, Kottmeier C, Corsmeier U, Blyth A, Craig G, Schumann U, Hagen M, Crewell S, DiGirolamo P, Flamant C, Miller M, Montani A, Mobbs S, Richard E, Rotach MW, Arpagaus M, Russchenberg H, Schlüssel P, König M, Gärtner V, Steinacker R, Dorninger M, Turner DD, Weckwerth T, Hense A, Simmer C. 2008. The Convective and Orographically induced Precipitation Study: A research and development project of the World Weather Research Program for improving quantitative precipitation forecasting in low-mountain regions. Bull. Amer. Meteorol. Soc. 89: $1477-1486$

Wulfmeyer V, Behrendt A, Kottmeier C, Corsmeier U, Barthlott C, Craig GC, Hagen M, Althausen D, Aoshima F, Arpagaus M, Bauer HS, Bennett L, Blyth A, Brandau C, Champollion C, Crewell S, Dick G, Di Girolamo P, Dorninger M, Dufournet Y, Eigenmann R, Engelmann R, Flamant C, Foken T, Gorgas T, Grzeschik M, Handwerker J, Hauck C, Höller H, Junkermann W, Kalthoff N, Kiemle C, Klink S, König M, Krauss L, Long CN, Madonna F, Mobbs S, Neininger B, Pal S, Peters G, Pigeon G, Richard E, Rotach MW, Russchenberg H, Schwitalla T, Smith V, Steinacker R, Trentmann J, Turner DD, van Baelen J, Vogt S, Volkert H, Weckwerth T, Wernli H, Wieser A, Wirth M. 2011. The Convective and Orographicallyinduced Precipitation Study (COPS): The scientific strategy, the field phase, and first highlights. Q. J. R. Meteorol. Soc. 137(S1):3-30, DOI: 10.1002/qj.752. 